\title{
The European Resource Centre for Alternatives in Higher Education
}

\author{
Jasmijn de Boo, ${ }^{1}$ David Dewhurst ${ }^{2}$ and Jan van der Valk' \\ ${ }^{1}$ NCA, Department Animals \& Society, Faculty of Veterinary Medicine, Utrecht University, Utrecht, The \\ Netherlands; ${ }^{2}$ Learning Technology Section, College of Medicine \& Veterinary Medicine, University of \\ Edinburgh, Edinburgh, UK
}

\begin{abstract}
Summary - The European Resource Centre for Alternatives in Higher Education (EURCA: http://www.eurca.org) is an exciting new project, which aims to enable teachers using animals in teaching to be more creative and innovative in their approach to teaching and learning, to foster high-quality training for science students, and to significantly reduce the number of animals used, often unnecessarily, in teaching. This will be achieved by: a) establishing a resource centre - a collection of mainly electronic alternatives, and taking this to relevant scientific meetings in Europe, where it would function as a drop-in advice centre for teachers; b) creating a network of academic teachers who actively use alternatives, to take responsibility for disseminating information about alternatives to other teachers in the European Union, to participate in the activity outlined above, and to share experiences and good practice; c) setting up an Internet website with an expansive, information-rich database (peer-reviews, demos, peer-evaluations, peer-recommendations, links to users, etc.) on selected "tried and tested" alternatives; and d) encouraging and promoting the findings of evaluative studies on the effectiveness of alternatives in higher education teaching and learning.
\end{abstract}

Key words: alternatives, database, higher education, resource centre, teaching.

Address for correspondence: J. de Boo, NCA, Department Animals \& Society, Faculty of Veterinary Medicine, Utrecht University, Yalelaan 17, 3584 CL Utrecht, The Netherlands.

E-mail: j.deboo@vet.uu.nl

\section{Introduction}

The notion of a European Resource Centre for Alternatives in Higher Education (EURCA) originated in an European Centre for the Validation of Alternative Methods (ECVAM) workshop, held in 1998, on "Alternatives to the Use of Animals in Higher Education" (1). The workshop participants identified:

1. A lack of detailed information about alternatives to the use of animals in education (e.g. reviews, results of evaluative studies, examples of support materials, teachers' experiences), as most existing databases presented only product information.

2. A need to actively encourage the use of alternatives by creating a Resource Centre with examples of alternatives and taking it to international conferences of science teachers for demonstration.

EURCA is thus about assembling a range of highquality alternatives, describing them in the database in a way that will help teachers to decide if they are likely to be useful to them and to promote the educational effectiveness of alternatives in teaching and learning in higher education (college, university level and beyond).

When considering specific alternatives for inclusion in the database, the following criteria are taken into account:

- they should reduce, refine or replace animal models in education, with an emphasis on replacement, and not just be an additional educational tool in teaching;

- they should have a pedagogical approach - for example, they should be interactive, provide students with opportunities to "design" an experiment, change experimental parameters and contain student-centred tasks and selfassessments;

- demonstration versions should be available (this will make decisions whether or not to purchase the product easier);

- recommendations of the alternatives by other teachers should be available; and

- support materials should be provided to help teachers to integrate the alternatives into teaching. 


\section{Dissemination of Information}

One of the primary goals of the EURCA project is to effectively disseminate information about alternatives and to provide an opportunity for teachers to get hands-on experience of them and to talk to teachers who have used them in their own teaching. This has been achieved by establishing a Resource Centre - a collection of high-quality alternatives (currently over 50 titles, including computer-based alternatives, videos, models and simulators) and a website containing descriptive information about them. The information and alternative models are being made available to teachers by:

1. Taking the Resource Centre to major conferences and scientific meetings where it will function as a drop-in advice centre for teachers. A display stand and laptop with installed ready-torun programs are being used to demonstrate alternative models. Other outreach activities include carrying out site visits to demonstrate good practice in the use of alternatives.

2. Maintaining an Internet website (http://www. eurca.org), which inter alia offers the following sections:

— the alternatives database (see below);

- background information on animals in education, including the ECVAM workshop report and a number of academic presentations relating to the issue of using animals and alternatives in education;

- a discussion board, which is a section on the EURCA website for teachers and students to discuss any topic related to the use of alternatives in education; and

- links to relevant organisations and more information about specific alternatives.

\section{The EURCA Alternatives Database}

Teachers need comprehensive information regarding the use of alternatives in their teaching to be able to assess the suitability of these alternatives. Furthermore, teachers do not wish to be overwhelmed with a large number of models; they are looking for the best alternative (1). The added value of the EURCA alternatives database, compared to other existing databases on alternatives in education, is illustrated by descriptions of pedagogical and practical advantages of alternatives over the traditional animal lab. Thus, the database contains standard product information, plus additional information such as:
- which learning objectives can be achieved by the alternative model;

- a description of the educational level and target group;

- any available support materials such as workbooks, additional assignments, etc.; and

- how the alternative may be used, e.g. duration of the alternative practical, which animal lab has been replaced (or how it will reduce the number of animals), whether the alternative can be modified by/for the users to meet specific requirements.

When applicable, the EURCA record is linked to the record number in the Norwegian Inventory of Alternatives (NORINA), a database with over 3500 educational models (http://oslovet.veths.no/NORINA). Finally, EURCA also indicates whether the alternative can be loaned from the International Network for Humane Education (InterNICHE; http://www. interniche.org/).

\section{Commissioned Peer Reviews}

To help teachers to decide if a particular alternative is likely to be suitable, EURCA commissions experts from the field to produce independent reviews of alternatives, which are then added to the database. Reviewers are provided with a standardised questionnaire, and each review form contains the following headings, with a subset of questions for items two to seven.

1. Summary.

2. Comparison of the alternative model with the real animal model.

3. User-friendliness of the alternative resource.

4. Potential contribution of the alternative resource to the Three $\mathrm{Rs}$.

5. Applicability in teaching situation.

6. Visual appearance.

7. Service provided by the supplier.

After publication of the review on the EURCA website, the developers of the alternative are invited to comment on the review, and other users of the alternative can also add comments. To date, most reviewers have been positive about the usefulness of these alternatives. Some less-positive comments have referred to lack of multiple lan- 
guage versions, availability, price and supplier service, quality, level of interactivity and whether the model can be integrated into an existing course.

\section{Building a European Network}

A vital aspect of EURCA's activities is to build a network across Europe of teachers who are enthusiastic about using alternatives in their own teaching and able to promote the use of alternatives in education in their own countries. They will thus become academic advocates in their country and represent EURCA at local and national conferences. They could further maintain contacts with local developers of alternatives and contribute to the discussion of implementation of alternatives in the curricula. EURCA has plans to organise a meeting for national contacts in 2003, to thoroughly brief them on the EURCA project and to discuss the roles of the national contacts.

\section{International Cooperation}

EURCA has strong links with both InterNICHE and NORINA through cooperation in identifying new alternatives, and up-dating information and links to each other's websites. Representatives of InterNiche and NORINA are members of the EURCA Advisory Board.

\section{Note Added in Proof}

The first meeting for national contacts was held in Poland in October 2003, at which several possibilities for the further promotion of alternatives in higher education were discussed. The activities of national contacts could include: attending national science meetings on EURCA's behalf, submitting abstracts, referring students and teachers to the EURCA website, developing alternative models, translating programs into their national language, and keeping track of developments in their country. Currently, there are 24 national contacts, 14 of whom represent European Union (EU) Member States. The network continues to expand and a thematic network in the EU has been proposed

\section{References}

1. van der Valk, J., Dewhurst, D., Hughes, I., Atkinson, J., Balcombe, J., Braun, H., Gabrielson, K., Gruber, F., Miles, J., Nab, J., Nardi, J., van Wilgenburg, H., Zinko, U. \& Zurlo, J. (1999). Alternatives to the use of animals in higher education. The report and recommendations of ECVAM workshop 33. ATLA 27, 39-52. 